\title{
Clinical implications of blood eosinophil count in patients with non-asthma-COPD overlap syndrome COPD
}

This article was published in the following Dove Press journal:

International Journal of COPD

17 August 2017

Number of times this article has been viewed

Jin Hwa Song,' Chang-Hoon

Lee, ' Jin Woo Kim, ${ }^{2}$ Won-Yeon

Lee, ${ }^{3}$ Ji Ye Jung, ${ }^{4}$ Joo Hun

Park, ${ }^{5}$ Ki Suck Jung, ${ }^{6}$ Kwang

$\mathrm{Ha}$ Yoo, ${ }^{7}$ Yong Bum Park, ${ }^{8}$

Deog Keom Kim ${ }^{9}$

'Division of Pulmonary and Critical Care Medicine, Department of Internal Medicine, Seoul National University Hospital,

${ }^{2}$ Division of Pulmonology, Department of Internal Medicine, College of Medicine, The Catholic University of Korea, Seoul,

${ }^{3}$ Department of Internal Medicine,

Yonsei University Wonju College of

Medicine, Wonju, Gangwon-do, ${ }^{4}$ Division

of Pulmonology, Department of Internal

Medicine, Severance Hospital, Yonsei

University College of Medicine, Seoul,

${ }^{5}$ Department of Pulmonary and Critical

Care Medicine, Ajou University School of

Medicine, Suwon, ${ }^{6}$ Division of Pulmonary

Medicine, Department of Internal Medicine,

Hallym University Sacred Heart Hospital,

Hallym University Medical School, Anyang,

Gyeonggi-do, ${ }^{7}$ Division of Pulmonary and

Critical Care Medicine, Department of

Internal Medicine, Konkuk University

Medical Center, Konkuk University School

of Medicine, ${ }^{8}$ Division of Pulmonary, Allergy

and Critical Care Medicine, Department

of Internal Medicine, Kangdong Sacred

Heart Hospital, 'Division of Pulmonary

and Critical Care Medicine, Department

of Internal Medicine, Seoul Metropolitan

Government-Seoul National University

Boramae Medical Center, Seoul National

University College of Medicine, Seoul,

Republic of Korea

Correspondence: Deog Keom Kim

Division of Pulmonary and Critical Care Medicine, Department of Internal Medicine,

Seoul Metropolitan Government-Seoul

National University Boramae Medical Center,

Seoul National University College of Medicine,

20 Boramaero-5-Gil, Dongjak-Gu, Seoul 0706I,

Republic of Korea

$\mathrm{Tel}+8228702228$

Fax +8228312826

Email kimdkmd@gmail.com
Background: Recent studies that assessed the relevance of the blood eosinophil count as a biomarker in patients with COPD may have overestimated it because they included patients with asthma-COPD overlap syndrome (ACOS). We investigated the clinical implications of the blood eosinophil count in patients with non-ACOS COPD.

Patients and methods: From a Korean COPD Subtype Study (KOCOSS) cohort, we selected patients with non-ACOS COPD after excluding ACOS patients according to Spanish criteria. Clinical characteristics and the incidence of moderate-to-severe exacerbation were compared among the four groups stratified according to the quartiles of blood eosinophil percent and count.

Results: Of the KOCOSS cohort of 1,132 patients with COPD, 467 non-ACOS COPD patients $(41.2 \%)$ with data of blood eosinophil count remained after excluding those with ACOS based on the Spanish definition. There was no difference in clinical characteristics among groups classified according to the quartiles of eosinophil percent and count. On multivariate logistic regression, eosinophil quartiles in percent and absolute count were not associated with the incidence of moderate-to-severe acute exacerbations of COPD (AECOPD). The eosinophil count did not affect the risk of AECOPD or forced expiratory volume in 1 second $\left(\mathrm{FEV}_{1}\right)$ changes according to exposure to inhaled corticosteroid (ICS). However, by increasing the cutoff value for the eosinophil count from $200 / \mu \mathrm{L}$ to $600 / \mu \mathrm{L}$, the odds ratio for risk of exacerbation increased serially from 0.82 to 2.96 on trend analysis.

Conclusion: In patients with non-ACOS COPD, the blood eosinophil count and percent were not associated with $\mathrm{FEV}_{1}$ changes, quality of life (QoL), AECOPD frequency, or response to ICS. The clinical implication of the blood eosinophil count should not be overestimated in patients with non-ACOS COPD.

Keywords: eosinophil, chronic obstructive lung disease, asthma, acute exacerbation, inhaled corticosteroid

\section{Introduction}

COPD is one of the leading causes of death and is associated with high medical costs in the USA. ${ }^{1}$ Acute exacerbations of COPD (AECOPD) are associated with poor quality of life (QoL), decreased health status, ${ }^{2}$ accelerated lung function decline, ${ }^{3}$ frequent hospitalization, and mortality ${ }^{4}$ of COPD patients. Current emerging concepts of biologic clusters in COPD exacerbations suggest that neutrophilic inflammation and eosinophilic inflammation are the main phenotypes of exacerbation. ${ }^{5}$ Several studies have reported the role of C-reactive protein $(\mathrm{CRP})^{6,7}$ procalcitonin, ${ }^{7}$ and leukocyte counts ${ }^{6}$ in predicting AECOPD. Eosinophilic bronchial inflammation, reflected by the blood 
eosinophil count, ${ }^{8}$ is the main target of inhaled corticosteroid (ICS) therapy. ${ }^{9-11}$ In addition, the blood eosinophil count is associated with an increased risk of moderate-to-severe exacerbations. ${ }^{8,9,12,13}$ According to previous studies that assessed the peripheral blood count, $>2 \%$ or 200 cells $/ \mu \mathrm{L}$ is the cutoff value for the prediction of exacerbation ${ }^{14}$ and is associated with a better outcome in the hospital and intensive care unit. ${ }^{15}$

Asthma-COPD overlap syndrome (ACOS), defined by recent studies ${ }^{16-19}$ as a condition that includes clinical features of both asthma and COPD, affects 5\%-55\% of COPD patients. ${ }^{20}$ In asthma, bronchial hyperresponsiveness is related to eosinophilic airway inflammation; ${ }^{21}$ both Spanish and ATS criteria included blood eosinophil level as a minor criterion for ACOS. ${ }^{17,19}$ Because previous studies of the eosinophil count in COPD did not exclude patients with ACOS, ${ }^{5,12,22}$ we assumed that the role of the peripheral eosinophil count may have been exaggerated.

In this study, we investigated whether the peripheral eosinophil count can predict clinical outcomes in cases of moderate-to-severe AECOPD, forced expiratory volume in 1 second $\left(\mathrm{FEV}_{1}\right)$ changes per year, and response to ICS/long-acting beta agonist (LABA) in patients with non-ACOS COPD.

\section{Patients and methods}

\section{Patients and study design}

The Korean COPD Subtype Study (KOCOSS) is an ongoing, prospective, observational COPD cohort study investigating the epidemiological characteristics and subtypes of
COPD. Nationwide, 28 hospitals are participating in South Korea (NCT02800499); a more detailed description of the cohort is available elsewhere. ${ }^{23}$ Briefly, patients were eligible if they were aged $>40$ years, had post-bronchodilator $\mathrm{FEV}_{1} /$ forced vital capacity $<0.7$, and had smoked $>10$ years. Final data were assessed on June 28, 2016.

ACOS was defined according to Spanish criteria ${ }^{19}$ as follows: 1) previously treated or diagnosed with asthma; 2) strongly positive bronchodilator response: FEV increase $>15 \%$ and $400 \mathrm{~mL}$ compared with pre-bronchodilator values; 3 ) previous history of atopy, allergic rhinitis, or atopic dermatitis; 4) blood eosinophil percentage $>5 \%$; and 5) a positive bronchodilator response: $12 \%$ and a $200-\mathrm{mL}$ increase in $\mathrm{FEV}_{1}$. In this analysis, criterion (5) was defined for a single visit because KOCOSS data were collected at the annual visit. A diagnosis of ACOS required meeting at least one major or two minor criteria.

After excluding patients with ACOS and unavailable information on the eosinophil count in the initial cohort, patients with non-ACOS COPD were enrolled in the final analysis (Figure 1). The final study population was stratified into four groups based on the quartiles of eosinophil count and percent. The clinical variables were then compared among the groups. This study was approved by the Institutional Review Board (IRB) of each hospital (Seoul National University Hospital IRB, Catholic Medical Center Central IRB, Yonsei University Wonju College of Medicine IRB, Severance Hospital IRB, Ajou University IRB, Hallym University Sacred Heart hospital IRB, IRB of Konkuk University Hospital, IRB of Kangdong Sacred Heart Hospital, IRB of Seoul National

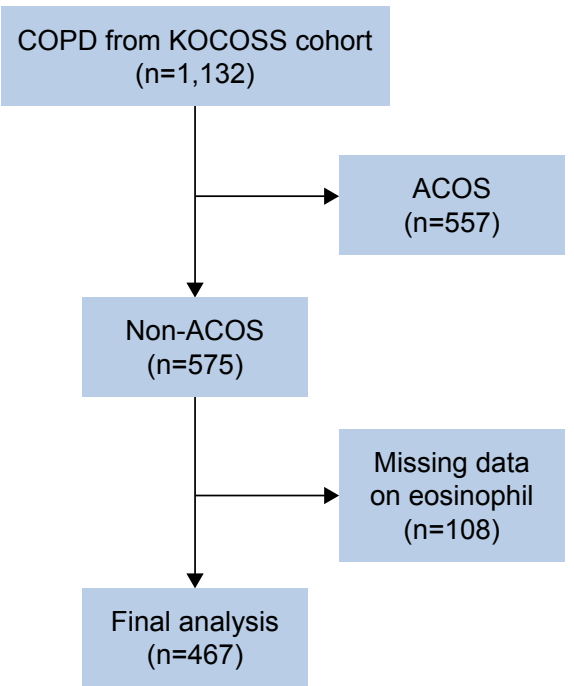

Major

1. History of asthma $(n=480 / 1,080)$

2. Very positive BDR $(n=26 / 1,132)$

Minor

1. $\lg E>100(n=106 / 209)$

2. History of atopy $(n=132 / 1,081)$

3. Positive BDR $(n=162 / 1,132)$

4. Blood eosinophil $>5 \%(n=174 / 923)$

Finally, ACOS, according to Spanish criteria $(n=557)$

Figure I Patient selection flow.

Abbreviations: KOCOSS, Korean COPD Subtype Study; ACOS, asthma-COPD overlap syndrome; BDR, bronchodilator response; IgE, immunoglobulin E. 
University Boramae Medical Center, Korea University Hospital IRB, Dongguk University Hospital IRB, Dong-A University Hospital IRB, Gachon University Gil Medical Center IRB, Kyung Hee University Hospital IRB, Kangbuk Samsung Hospital IRB, IRB of the Kangwon National University Hospital, Kyungpook National University Hospital IRB, Gyeongsang National University Hospital IRB, Pusan National University Hospital IRB, Soonchunhyang University Bucheon Hospital IRB, Pochon CHA University Hospital IRB, IRB of Eulji General Hospital, Samsung Medical Center IRB, IRB of Ulsan University Asan Hospital, Soonchunhyang University Seoul Hospital IRB, Yeungnam University Hospital IRB, Inha University Hospital Institutional Review of Board, IRB of Inje University Hospital, Chonbuk National University Hospital IRB, and IRB of Jeju National University Hospital). All patients provided written informed consent. We also obtained the approval of patient's medical records from each center, and confidentiality of patients was maintained.

Group A comprised patients with low risk and fewer symptoms (Global Initiative for Chronic Obstructive Lung Disease [GOLD] 2007 stage 1 or 2 and/or 0-1 exacerbations per year and Modified British Medical Research Council [mMRC] grade $0-1$ or COPD Assessment Test [CAT] score 10). Group B (low risk, more symptoms) was characterized by GOLD 2007 stage 1 or 2 and/or 0-1 exacerbations per year and mMRC grade 2 or CAT score 10 . Groups C and D were high-risk groups. Both were characterized by GOLD 2007 stage 3 or 4 and/or $>2$ exacerbations per year. Group C involved fewer symptoms (mMRC grade $0-1$ or CAT score 10) than group D (mMRC grade 2 or CAT score 10$)$.

\section{Measurements}

Demographic variables, including age, sex, body mass index (BMI), and smoking history, were collected. Laboratory data such as spirometric data and complete blood count (CBC) with differential count were collected. QoL was measured using St George's Respiratory Questionnaire (SGRQ) and the CAT. Information on inhaled respiratory medicine, including ICS/LABA and long-acting muscarinic antagonist (LAMA), was reported. We also measured the frequency of AECOPD with moderate-to-severe severity. Moderateto-severe AECOPD was defined as COPD requiring antibiotics in outpatient clinics, emergency room admission or admission due to an increased quantity of sputum, purulent changes in sputum, or aggravation of dyspnea in the previous 12 months. To test the association between COPD subgroups or severity and eosinophil quartiles, the associations were tested according to the COPD classification by the GOLD in 2007 and $2014 .^{24}$

\section{Statistical analysis}

The statistical analyses were performed using Stata 13.0 (StataCorp 2013, Stata Statistical Software: Release 13; StataCorp LP, College Station, TX, USA). Categorical variables were described as number (percentage), and continuous variables as mean \pm standard deviation (SD). The study population was stratified with the quartiles of eosinophil count and percent. The clinical characteristics of each group were compared using Pearson's chi-square test and Fisher's exact test for categorical variables and one-way ANOVA and Kruskal-Wallis tests for continuous variables. Multivariate logistic regression analysis was used to identify the role of eosinophil quartiles in predicting AECOPD. The prediction models were adjusted for age, sex, pack-years, $\mathrm{BMI}, \mathrm{ICS} / \mathrm{LABA}$ use, and initial $\mathrm{FEV}_{1}$ predicted $\%$ acquired at the first visit.

\section{Results}

Among 1,132 patients with COPD, 557 (49.2\%) were diagnosed with ACOS based on Spanish criteria. Of the patients with ACOS, $88.5 \%(n=480)$ had a history of asthma and $31.2 \%(n=174)$ had a blood eosinophil percentage $>5 \%$ (Figure 1). Excluding patients with ACOS, 467 patients with non-ACOS were included in the final analyses. The median eosinophil percent in the study population was $2.4 \%$ (interquartile range [IQR] 1.3\%-3.8\%), and the median absolute count was 166.5 cells/ $\mu \mathrm{L}$ (IQR 89.6-272.8 cells $/ \mu \mathrm{L}$ ). Blood eosinophil counts were distributed in the ranges of 0-89 cells/ $\mu \mathrm{L}, 89-166$ cells/ $\mu \mathrm{L}, 167-273$ cells/ $\mu \mathrm{L}$, and $263-$ 2,213 cells/ $\mu \mathrm{L}$ in each quartile. As shown in Figure 2, the majority of patients with non-ACOS COPD had an eosinophil count of $<500$ cells $/ \mu \mathrm{L}$, while the fourth quartile included relatively broad ranges for eosinophil percent and count.

\section{Baseline characteristics of patients with non-ACOS COPD according to eosinophil count}

The baseline characteristics of patients with non-ACOS COPD stratified by eosinophil quartiles are compared in Table 1 . There were no statistically significant differences in age, sex, pack-years, or BMI among the groups. There was also no significant difference in spirometric data or QoL score, including SGRQ and CAT. Neither the white blood cell (WBC) nor the proportion of neutrophils showed any trends by increasing eosinophil quartiles, although the WBC counts 

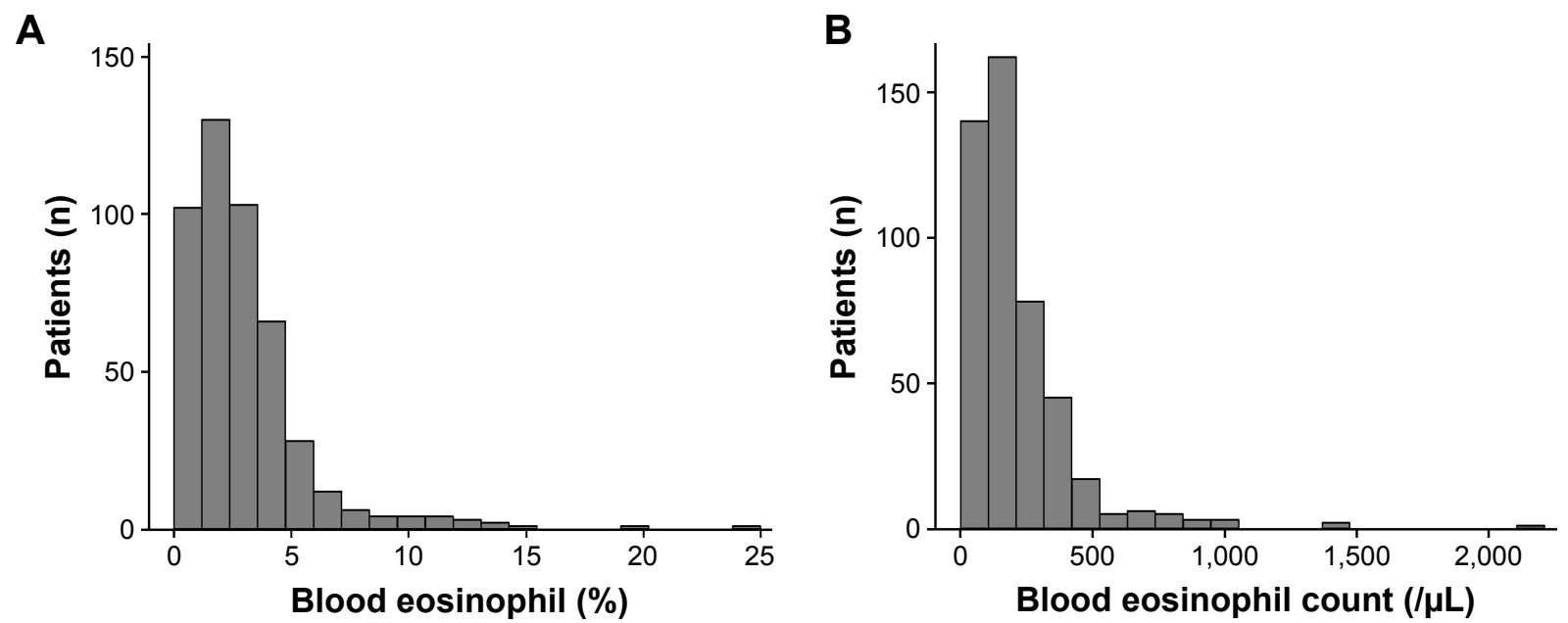

C
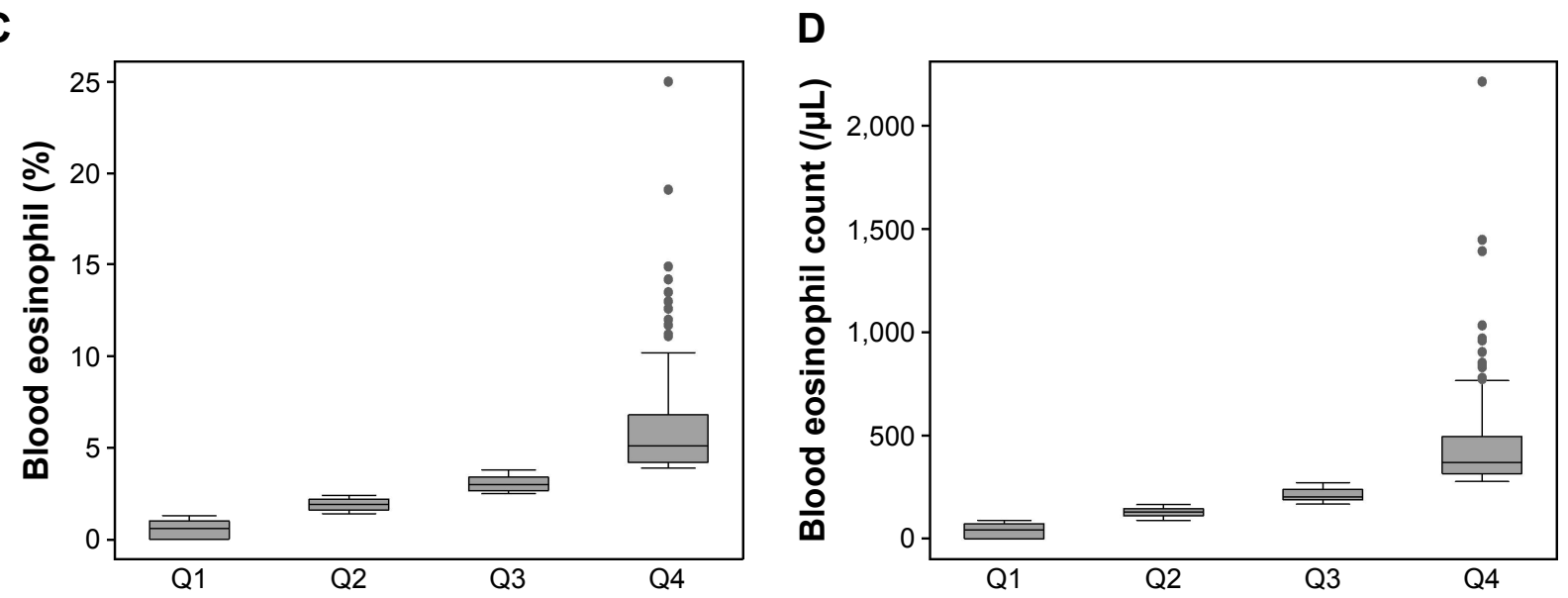

Figure 2 Distribution of eosinophil count in study population.

Notes: Histograms of eosinophil percentage $(\mathbf{A})$ and absolute eosinophil count $(\mathbf{B})$ in peripheral blood. (C) A box and whisker plot of the blood eosinophil percentages for the groups classified according to eosinophil percent quartiles. (D) A box and whisker plot of the absolute eosinophil count for the groups classified according to eosinophil count quartiles.

Abbreviation: $\mathrm{Q}$, quartile.

were significantly higher in the first quartile than in the other groups (Q1: $8.4 \pm 3.4\left[\times 10^{3} / \mathrm{L}\right], \mathrm{Q} 2: 7.2 \pm 2.68, \mathrm{Q} 3: 7.6 \pm 2.0$, and Q4: 8.1 $\pm 2.1, P=0.003])$. The proportion of moderateto-severe exacerbations over the previous year was highest in the first quartile at $38 / 117(41.4 \% ; P=0.007)$. Although there was no linear trend in clinical characteristic variables according to quartiles, patients in the first and fourth quartiles showed more severe airflow limitation, higher neutrophil percentages, higher CRP, and a higher incidence of AECOPD than those in the second and third quartiles. Additionally, the use of bronchodilators, including LAMA, LABA, and ICS, did not differ among the groups.

\section{Association between quartiles of eosinophil count and the severity or subgroups of COPD}

Upon comparison of the quartiles in eosinophil count and percent according to the severity of airflow limitation
( $\mathrm{FEV}_{1} \%$ predicted) and subgroups of COPD defined by GOLD, we found no significant difference or association with previously suggested severity criteria $(P=0.297$ and $P=0.61$, respectively; Figure 3 ). The prevalence of patients with each eosinophil quartile was similar through stages I-IV as defined by GOLD 2007 ( $P=0.757$; Table 2 and Figure 4).

\section{Impact of eosinophil count on the risk of moderate-to-severe AECOPD}

We analyzed patients who were followed up for 1 year to determine the association with acute exacerbations and blood eosinophil count. In univariate analysis of the effects of the blood eosinophil count on the risk of moderate-to-severe AECOPD, absolute eosinophil count and quartiles of blood eosinophil counts were not associated with a risk of acute exacerbation in this study group, whereas a lower $\mathrm{FEV}_{1}$ (predicted $\%$; odds ratio [OR] 0.97, 95\% confidence interval 
Table I Baseline characteristics of study population

\begin{tabular}{|c|c|c|c|c|c|c|}
\hline Variables & Total $(\mathrm{N}=467)$ & $Q \mid(n=|| 7)$ & Q2 (n=|l7) & Q3 (n=II7) & Q4 (n=| |6) & $P$-value \\
\hline Age (years) & $69.5 \pm 7.4$ & $69.2 \pm 7.6$ & $69.5 \pm 7.6$ & $69.2 \pm 7.2$ & $70.0 \pm 7.3$ & 0.784 \\
\hline Sex (male) & 448 (95.9\%) & III (94.9\%) & II 5 (98.3\%) & 109 (93.2\%) & II 3 (97.4\%) & 0.175 \\
\hline Pack-year & $47.5 \pm 25.1$ & $50.1 \pm 27.6$ & $46.7 \pm 22.1$ & $45.3 \pm 25.9$ & $47.8 \pm 24.8$ & 0.532 \\
\hline BMI $\left(\mathrm{kg} / \mathrm{m}^{2}\right)$ & $22.7 \pm 3.4$ & $22.3 \pm 3.3$ & $22.7 \pm 3.2$ & $23.3 \pm 3.6$ & $22.6 \pm 3.3$ & 0.148 \\
\hline \multicolumn{7}{|l|}{ Spirometry } \\
\hline $\mathrm{FEV}_{1} \%$ pred & $55.5 \pm 18.0$ & $53.5 \pm 16.7$ & $56.3 \pm 17.7$ & $56.8 \pm 18.7$ & $55.3 \pm 18.7$ & 0.488 \\
\hline FVC\% pred & $81.7 \pm 17.4$ & $79.3 \pm 18.5$ & $83.0 \pm 16.2$ & $82.4 \pm 16.7$ & $82.2 \pm 18.2$ & 0.355 \\
\hline BDR\% pred & $5.97 \pm 8.78$ & $6.5 \pm 10.3$ & $5.7 \pm 7.3$ & $6.7 \pm 8.2$ & $4.9 \pm 9.1$ & 0.390 \\
\hline $\mathrm{RV} / \mathrm{TLC} \%$ & $47.0 \pm 16.4$ & $49.1 \pm 17.0$ & $45.0 \pm 14.7$ & $46.4 \pm 16.3$ & $47.6 \pm 17.9$ & 0.417 \\
\hline WBC $\left(\times 10^{3} / L\right)$ & $7.8 \pm 2.6$ & $8.4 \pm 3.4$ & $7.2 \pm 2.6$ & $7.6 \pm 2.0$ & $8.1 \pm 2.1$ & 0.003 \\
\hline Neutrophil\% & $60.3 \pm 33.8$ & $61.7 \pm 20.5$ & $59.3 \pm 10.9$ & $57.4 \pm 9.2$ & $63.0 \pm 62.9$ & 0.603 \\
\hline CRP & $2.2 \pm 7.4$ & $2.7 \pm 5.7$ & $2.1 \pm 6.5$ & $1.1 \pm 1.8$ & $2.8 \pm 11.4$ & 0.590 \\
\hline SGRQ total & $36.0 \pm 18.8$ & $37.2 \pm 20.4$ & $37.6 \pm 17.8$ & $33.0 \pm 18.1$ & $36.3 \pm 18.8$ & 0.234 \\
\hline CAT total & $16.4 \pm 7.7$ & $17.8 \pm 8.3$ & $16.5 \pm 7.5$ & $15.0 \pm 7.4$ & $16.4 \pm 7.3$ & 0.055 \\
\hline AECOPD (Fr/year) & $2.1 \pm 1.8$ & $2.1 \pm 2.0$ & $1.9 \pm 1.5$ & $2.0 \pm 1.4$ & $2.1 \pm 2.1$ & 0.899 \\
\hline AECOPD in I year & 148 (31.9\%) & 38 (4I.4\%) & $30(26.1 \%)$ & $36(30.8 \%)$ & $34(29.3 \%)$ & 0.007 \\
\hline LAMA & $275(71.8 \%)$ & 59 (68.6\%) & $73(73.0 \%)$ & 70 (7I.4\%) & $73(73.7 \%)$ & 0.874 \\
\hline ICS/LABA & $200(53.6 \%)$ & $56(57.1 \%)$ & $5 \mathrm{I}(54.8 \%)$ & $50(55.6 \%)$ & $43(46.7 \%)$ & 0.488 \\
\hline LABA & $89(24.7 \%)$ & $13(16.3 \%)$ & $27(28.7 \%)$ & $23(25.6 \%)$ & $26(27.1 \%)$ & 0.239 \\
\hline
\end{tabular}

Note: Data are presented as mean \pm SD or $n(\%)$.

Abbreviations: Q, quartile; BMI, body mass index; FEV , forced expiratory volume in I second; \% pred, \% predicted; FVC, forced vital capacity; RV, residual volume; TLC, total lung capacity; BDR, bronchodilator response; WBC, white blood cell; CRP, C-reactive protein; SGRQ, St George's Respiratory Questionnaire; CAT, COPD Assessment Test; AECOPD, acute exacerbation of COPD; LAMA, long acting muscarinic antagonist; ICS, inhaled corticosteroid; LABA, long-acting beta 2 agonist; SD, standard deviation.

[CI] $0.95-0.99, P$-value 0.001$)$ and use of ICS/LABA at enrollment (OR 2.25, 95\% CI 1.15-4.44, P-value 0.019) were associated with an increasing risk of acute exacerbation (Table 3).

After adjusting for age, sex, pack-years, BMI, and initial $\mathrm{FEV}_{1}$, an eosinophil count of $>600 / \mu \mathrm{L}$ was associated with moderate-to-severe AECOPD (OR 3.59, 95\% CI 1.00-12.8, $P$-value 0.050$)$. However, upon adjustment based on
ICS/LABA use, the statistical significance was lost (OR 1.66, 95\% CI 0.43-6.40, $P$-value 0.460; Table 3).

When the risk of AECOPD was tested upon stratifying the absolute eosinophil count as $200,300,400,500$, or $600 / \mu \mathrm{L}$, the eosinophil count was not a significant risk factor for AECOPD (Table 3). However, by increasing the cutoff value for the eosinophil count from $200 / \mu \mathrm{L}$ to $600 / \mu \mathrm{L}$, the OR for risk of exacerbation increased serially from 0.82 to 2.96 .
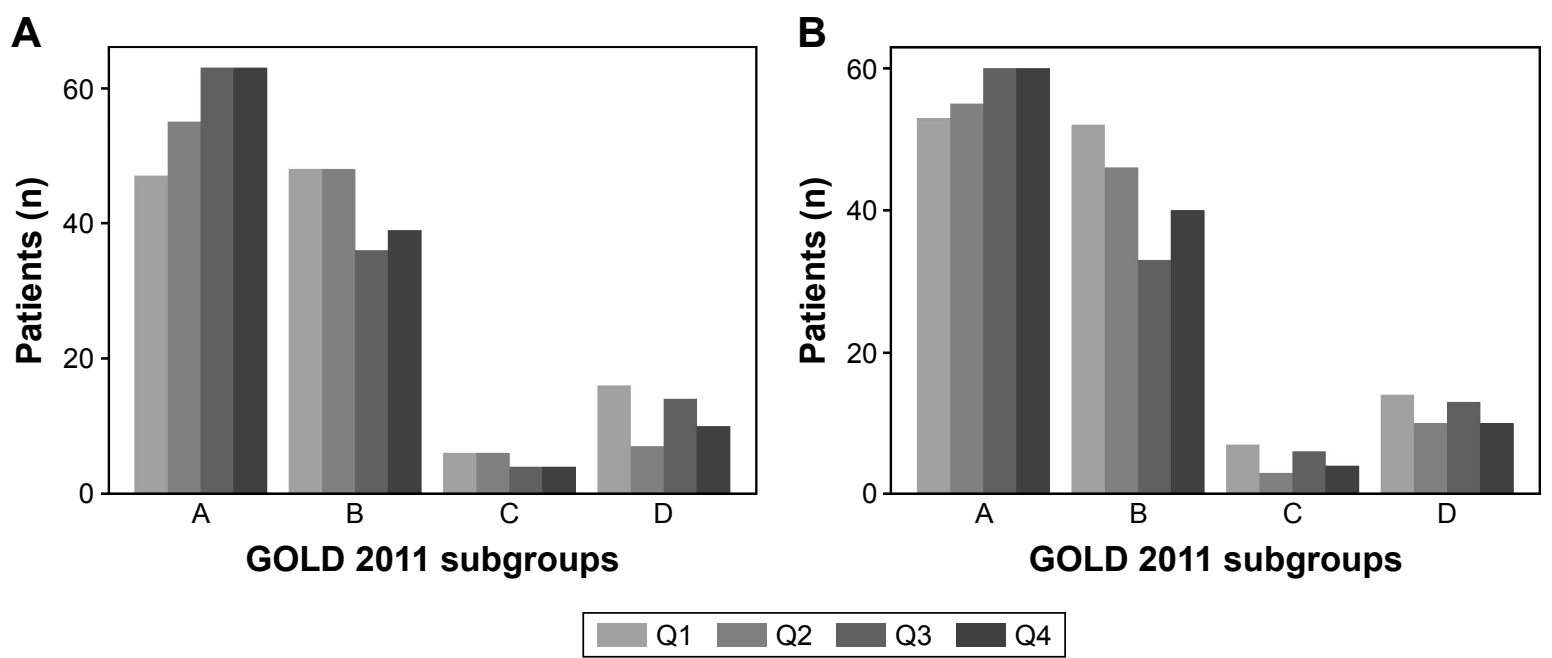

Figure 3 Distribution of eosinophil quartiles in GOLD subgroups of COPD.

Notes: (A) Distribution of blood eosinophil count quartile in each GOLD 201 I subgroup. (B) Distribution of blood eosinophil (\%) quartile in each GOLD 20II subgroup.

Abbreviations: GOLD, Global Initiative for Chronic Obstructive Lung Disease; Q, quartile. 
Table 2 Distribution of eosinophil count quartiles in subgroups of GOLD stages

\begin{tabular}{|c|c|c|c|c|c|}
\hline $\begin{array}{l}\text { Blood eosinophil } \\
\text { count quartile }\end{array}$ & GOLD stage I & GOLD stage II & GOLD stage III & GOLD stage IV & $P$-value \\
\hline Q। (n=| |7), n (\%) & $7(15.6)$ & $62(25.9)$ & $40(25.5)$ & $9(30.8)$ & 0.757 \\
\hline Q2 (n=I I7), n (\%) & $10(22.2)$ & $61(25.5)$ & $40(25.5)$ & $6(23.1)$ & \\
\hline Q3 (n=I|7), n (\%) & $17(37.8)$ & $58(24.3)$ & $37(23.6)$ & $5(19.2)$ & \\
\hline Q4 (n=I I6), n (\%) & II (24.4) & $58(24.3)$ & $40(25.5)$ & 7 (26.9) & \\
\hline
\end{tabular}

Abbreviations: GOLD, Global Initiative for Chronic Obstructive Lung Disease; Q, quartile.

\section{Impact of eosinophil count on FEV , changes per year}

Although the follow-up period was limited to 1 year, the $\mathrm{FEV}_{1}$ change was measured according to the eosinophil quartiles. The absolute count of $200 / \mu \mathrm{L}$ had no impact on $\mathrm{FEV}_{1}$ changes during the follow-up period (Table 4). Nevertheless, patients with an eosinophil count of $>600 / \mu \mathrm{L}$ had a decreased $\mathrm{FEV}_{1}$ (Table 4).

\section{Association between eosinophil count and treatment response to ICS/LABA}

The treatment response to ICS/LABA according to eosinophil count was assessed for the risk of AECOPD and $\mathrm{FEV}_{1}$ changes for 1 year. The mean eosinophil count and percent were not different (user vs non-user $213.3 \pm 16.1$ vs $204.4 \pm 14.9, P=0.685 ; 3.0 \pm 0.5$ vs $2.8 \pm 0.2, P=0.420$ ) according to the use of ICS/LABA at enrollment. While initial ICS/LABA use was associated with an increased risk of moderate-to-severe exacerbation of COPD (OR 2.25, 95\%

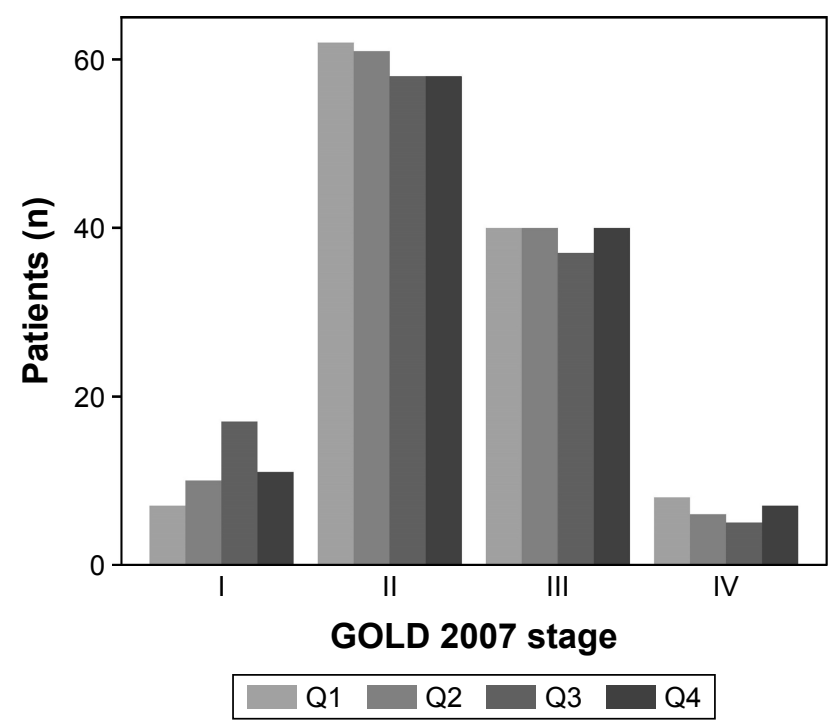

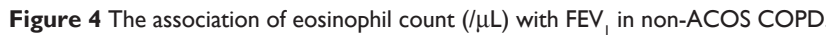
Note: Distribution of eosinophil count quartile in each GOLD stages.

Abbreviations: $\mathrm{FEV}_{1}$, forced expiratory volume in I second; ACOS, asthmaCOPD overlap syndrome; GOLD, Global Initiative for Chronic Obstructive Lung Disease; Q, quartile.
CI 1.15-4.44, $P$-value 0.019 ) on univariate analyses (Table 3), the statistical significance disappeared when the model was adjusted according to age, sex, BMI, pack-years, and initial $\mathrm{FEV}_{1}$ (Table 5). When the population was stratified based on eosinophil counts' cutoff value of $200 / \mu \mathrm{L}$ and exposure to ICS/LABA, the FEV 1 change was not different among strata as in the test for risk of AECOPD (Table 6 and Figure 5). In patients with eosinophil counts $>200 / \mu \mathrm{L}$, incidence rate ratio (IRR) $(95 \% \mathrm{CI})$ was not different between ICS/LABA

Table 3 The effects of blood eosinophil count on the moderateto-severe acute exacerbation of non-ACOS COPD

\begin{tabular}{|c|c|c|}
\hline Variables & OR $(95 \% \mathrm{Cl})$ & $P$-value \\
\hline \multicolumn{3}{|l|}{ Univariate analysis } \\
\hline Age (years) & $1.00(0.96-1.04)$ & 0.972 \\
\hline Sex (male) & $1.20(0.25-5.87)$ & 0.814 \\
\hline Pack-year & $1.00(0.98-1.01)$ & 0.577 \\
\hline BMI $\left(\mathrm{kg} / \mathrm{m}^{2}\right)$ & $0.98(0.90-1.07)$ & 0.696 \\
\hline ICS/LABA use & $2.25(1.15-4.44)$ & 0.019 \\
\hline $\mathrm{FEV}_{1} \%$ pred & $0.97(0.95-0.99)$ & 0.001 \\
\hline Eosinophil count $(/ \mu \mathrm{L})$ & $1.00(0.99-1.00)$ & 0.948 \\
\hline \multicolumn{3}{|l|}{ Eosinophil count quartile* } \\
\hline QI & Reference & \\
\hline Q2 versus QI & $0.94(0.40-2.20)$ & 0.882 \\
\hline Q3 versus QI & $0.57(0.22-1.48)$ & 0.253 \\
\hline Q4 versus QI & I.II (0.48-2.56) & 0.809 \\
\hline Eosinophil $>200 / \mu \mathrm{L}$ & $0.82(0.44-1.54)$ & 0.544 \\
\hline Eosinophil $>300 / \mu \mathrm{L}$ & $1.18(0.59-2.39)$ & 0.633 \\
\hline Eosinophil $>400 / \mu \mathrm{L}$ & $1.34(0.53-3.40)$ & 0.538 \\
\hline Eosinophil $>500 / \mu \mathrm{L}$ & $2.19(0.69-7.01)$ & 0.185 \\
\hline Eosinophil $>600 / \mu \mathrm{L}$ & $2.96(0.87-10.1)$ & 0.083 \\
\hline \multicolumn{3}{|l|}{ Multivariate analysis } \\
\hline Eosinophil $>600 / \mu \mathrm{L}^{\#}$ & $3.59(1.00-12.8)$ & 0.050 \\
\hline Eosinophil $>600 / \mu \mathrm{L}^{\ddagger}$ & $1.66(0.43-6.40)$ & 0.460 \\
\hline Eosinophil count $(/ \mu \mathrm{L})^{\#}$ & $1.0(0.99-1.00)$ & 0.768 \\
\hline Eosinophil count $(/ \mu \mathrm{L})^{\ddagger}$ & $1.0(0.99-1.00)$ & 0.815 \\
\hline
\end{tabular}

Notes: *ORs and $95 \% \mathrm{Cls}$ for patients in Q2, Q3, and Q4 of eosinophil count are presented, with patients in the lowest quartile serving as the reference. QI $(n=42$, median 47.2, IQR 7.2-71.0), Q2 ( $\mathrm{n}=63$, 129.2 [106.4-|47.2]), Q3 ( $\mathrm{n}=56,202.7$ [191.4-243.2]), and Q4 ( $\mathrm{n}=63,370.5$ [320.8-48I.I]). *ORs adjusted with age, sex, pack-year, BMI, and initial FEV \% pred at enrollment. ¥ORs adjusted with age, sex, pack-year, BMI, and ICS/LABA use at enrollment.

Abbreviations: ACOS, asthma-COPD overlap syndrome; OR, odds ratio; $\mathrm{Cl}$, confidence interval; BMI, body mass index; ICS, inhaled corticosteroid; LABA, long-acting beta 2 agonist; FEV , forced expiratory volume in I second; \% pred, \% predicted; IQR, interquartile range; $Q$, quartile. 
Table 4 FEV, change in subgroups stratified according to blood eosinophil count

\begin{tabular}{|c|c|c|c|c|}
\hline Blood eosinophil count quartile $(/ \mu \mathrm{L})$ & FEV, change (\%) & $P$-value & FEV , change $(\mathrm{mL})$ & $P$-value \\
\hline Eosinophil count $\leq 200 / \mu \mathrm{L}(\mathrm{n}=107)$ & $-0.2 \pm 11.8(-2.5-2.1)$ & 0.215 & $-10.4 \pm 386.0(-84.4-63.6)$ & 0.244 \\
\hline Eosinophil count $>200 / \mu \mathrm{L}(\mathrm{n}=77)$ & $2.0 \pm I I .8(-0.7-4.7)$ & & $52.2 \pm 316.3(-19.6-124.0)$ & \\
\hline Eosinophil count $\leq 600 / \mu \mathrm{L}(\mathrm{n}=175)$ & $0.3 \pm 11.2(-1.4-1.9)$ & 0.022 & $3.8 \pm 335.3(-46.4-53.8)$ & 0.044 \\
\hline Eosinophil count $>600 / \mu \mathrm{L}(\mathrm{n}=9)$ & $9.5 \pm 19.2(-5.2-24.2)$ & & $250.0 \pm 66 \mid .4(-258.4-758.4)$ & \\
\hline
\end{tabular}

Note: Data presented as FEV, change per year-mean \pm standard deviation ( $95 \%$ confidence interval).

Abbreviation: $\mathrm{FEV}_{1}$, forced expiratory volume in I second.

user and non-user (1.12 [0.66-1.91] vs 0.32 [0.00-20.88], $P=0.657)$ and lower than $200 / \mu \mathrm{L}(0.86[0.48-1.56]$ vs 3.26 [0.36-290.9], $P=0.623$ ).

\section{Discussion}

Against the background of an increasing focus being placed on blood eosinophils and their significance in COPD, this study elucidated the clinical significance of the blood eosinophil count in patients with non-ACOS COPD. Our results indicated that neither the absolute blood eosinophil count nor the quartiles were associated with the risk of AECOPD, $\mathrm{FEV}_{1}$ changes, or therapeutic response to ICS in patients with non-ACOS COPD.

To the best of our knowledge, this was the first analysis of the clinical implication of the blood eosinophil count in nonACOS COPD patients from a nationwide cohort. We believe that the results are relevant to clinical practice. Generally, eosinophilic inflammation is regarded as a pivotal etiological factor in the asthmatic component of COPD. ${ }^{25,26}$ Additionally, multiple reports have suggested the usefulness of the eosinophil count in predicting the therapeutic response to ICS. ${ }^{9}, 13,27$ However, before generalization of these results, we should consider the following points. COPD includes various phenotypes or endotypes and blood eosinophil count is not the only important biomarker; the reports referenced earlier did not discuss the phenotypes in which blood eosinophilia may be useful. ${ }^{10,11,22}$ To date, among the various phenotypes of COPD, ACOS has been regarded as a COPD phenotype that is characterized by asthmatic components, such as a high eosinophil count, an increased IgE level, a positive bronchodilator response, and a history of allergic disease ${ }^{28} \mathrm{COPD}$ is a precise phenotype that can be diagnosed clinically, and the criteria for ACOS include the components that indicate responsiveness to ICS. Therefore, to generalize the usefulness of the blood eosinophil count as a biomarker in COPD, it is necessary to verify that this count is also a useful biomarker in other patients, excluding ICS-susceptible patients such as those with ACOS. However, when we analyzed only patients with non-ACOS COPD, the alleged clinically significant role of the blood eosinophil count was absent. Therefore, the usefulness of the blood eosinophil count should not be overestimated in these patients.

Since the eosinophil count and related allergic components are included in the diagnosis of ACOS and the more predictable factors for a specific phenotype have not been confirmed, there may be controversy over the exclusion of ACOS patients from our analysis. Nevertheless, the distributions of blood eosinophil percent (median value $2.4 \%$, IQR $2.3 \%-3.8 \%)$ and absolute count $(167 / \mu \mathrm{L}$, range 90-273/ $\mu \mathrm{L})$ in South Korean non-ACOS COPD patients

Table 5 FEV, change in subgroups stratified according to blood eosinophil counts and use of ICS/LABA

\begin{tabular}{|c|c|c|c|c|}
\hline & FEV, change (\%) & $P$-value & FEV , change $(\mathrm{mL})$ & $P$-value \\
\hline \multicolumn{5}{|l|}{ Eosinophil count $\leq 200 / \mu \mathrm{L}$} \\
\hline ICS/LABA use $(n=60)$ & $-0.8 \pm 11.5(-3.8-2.2)$ & 0.745 & $-33.3 \pm 459.7(-182.3-115.7)$ & 0.769 \\
\hline No use of ICS/LABA $(n=39)$ & $0.01 \pm 12.4(-4.0-4.0)$ & & $-9.2 \pm 352.7(-100.3-81.9)$ & \\
\hline \multicolumn{5}{|l|}{ Eosinophil count $>200 / \mu \mathrm{L}$} \\
\hline ICS/LABA use $(n=34)$ & $0.7 \pm I \mid .2(-3 . \mid-4.6)$ & 0.290 & $100.6 \pm 385.2(-33.8-235.0)$ & 0.339 \\
\hline No use of ICS/LABA $(n=35)$ & $3.9 \pm 13.3(-0.8-8.5)$ & 0.290 & $24.3 \pm 263.8(-66.3-114.9)$ & \\
\hline \multicolumn{5}{|l|}{ Eosinophil count $\leq 600 / \mu \mathrm{L}$} \\
\hline ICS/LABA use $(n=7 I)$ & $1.2 \pm 11.7(-1.6-4.0)$ & 0.3022 & $6.3 \pm 379.0(-83.4-96.0)$ & 0.864 \\
\hline No use of ICS/LABA $(n=88)$ & $-0.7 \pm 11.2(-3.0-1.7)$ & & $-3.2 \pm 320.2(-71.0-64.7)$ & \\
\hline \multicolumn{5}{|l|}{ Eosinophil count $>600 / \mu \mathrm{L}$} \\
\hline ICS/LABA use $(n=2)$ & $5.5 \pm 13.1(-6.6-17.6)$ & 0.558 & $835 \pm I, 364.7(-11,426.5-13,096.5)$ & 0.558 \\
\hline No use of ICS/LABA $(n=7)$ & $23.5 \pm 37.5(-313.2-360.2)$ & & $|34.2 \pm 355|.(-245.6-4|| .3)$ & \\
\hline
\end{tabular}

Note: Data presented as FEV, change per year-mean \pm standard deviation ( $95 \%$ confidence interval).

Abbreviations: $\mathrm{FEV}_{1}$, forced expiratory volume in I second; ICS, inhaled corticosteroid; LABA, long-acting beta 2 agonist. 
Table 6 Impact of eosinophil count on moderate-to-severe acute exacerbation rates in COPD patients according to the exposure to ICS/LABA

\begin{tabular}{|c|c|c|}
\hline & $\operatorname{IRR}(95 \% \mathrm{CI})^{\mathrm{a}}$ & $\begin{array}{l}P \text {-value for } \\
\text { interaction }\end{array}$ \\
\hline \multicolumn{3}{|l|}{ Eosinophil count $\leq 200 / \mu \mathrm{L}$} \\
\hline ICS/LABA use $(n=60)$ & $1.12(0.66-1.91)$ & 0.657 \\
\hline No use of ICS/LABA $(n=39)$ & $0.32(0.00-20.88)$ & \\
\hline \multicolumn{3}{|l|}{ Eosinophil count $>200 / \mu \mathrm{L}$} \\
\hline ICS/LABA use $(n=34)$ & $0.86(0.48-1.56)$ & 0.623 \\
\hline No use of ICS/LABA $(n=35)$ & $3.26(0.36-290.9)$ & \\
\hline
\end{tabular}

Note: aModels adjusted for age, sex, BMI, pack-year, and FEV $\%$ pred at enrollment. Abbreviations: ICS, inhaled corticosteroid; LABA, long-acting beta 2 agonist; IRR, incidence rate ratio; $\mathrm{Cl}$, confidence interval.

were similar to those in previous Copenhagen cohort studies that included ACOS patients (median blood eosinophil 2.6\%, IQR 1.6\%-3.7\%; blood eosinophil count 200/ $\mathrm{L}$, range $120-300 / \mu \mathrm{L})^{12}$ and a US-based cohort (median blood eosinophil 2.6\%, IQR 1.8\%-4.0\%). ${ }^{26}$ Additionally, although there were more patients with a blood eosinophil count $>3 \%-5 \%$ than in previous reports that included patients with non-ACOS COPD in the COPD History Assessment in Spain (CHAIN) cohort (35.8\% vs $26.7 \%$ for an eosinophil count $>3 \% ; 12.6 \%$ vs $5.2 \%$ for an eosinophil count $>5 \%$ ), ${ }^{19}$ the blood eosinophil count was not associated with COPD subgroups, the risk of
$\mathrm{AECOPD}, \mathrm{FEV}_{1}$ changes per year, or responsiveness to ICS in the non-ACOS COPD patients.

This finding implies that the eosinophilic activity of patients with non-ACOS COPD may be different from that of patients with asthma or ACOS. In patients with allergic asthma, the eosinophilic activity may be altered by the enhanced production of spontaneous reactive oxygen species, increased chemotaxis, and diminished apoptosis, ${ }^{29}$ while the eosinophilic activity in COPD is not reported. Recently, a patient-level meta-analysis reported that patients with an eosinophil count of $<2 \%$ had a higher risk of pneumonia, ${ }^{30}$ which may reflect the importance of other inflammatory cells such as neutrophils, which has a key role in immune reaction of COPD, ${ }^{31}$ in this subpopulation.

Although we were unable to confirm the blood eosinophil count as an essential biomarker in non-ACOS COPD, when the cutoff value of the eosinophil count was changed from 200 to 600 cells $/ \mu \mathrm{L}$, the risk of AECOPD showed a tendency to increase gradually without statistical significance. This finding suggests that the cutoff value of the eosinophil count should be changed if it is used as a biomarker in patients with non-ACOS COPD.

Despite its clinically important and interesting findings, this study had some limitations. First, the final sample size
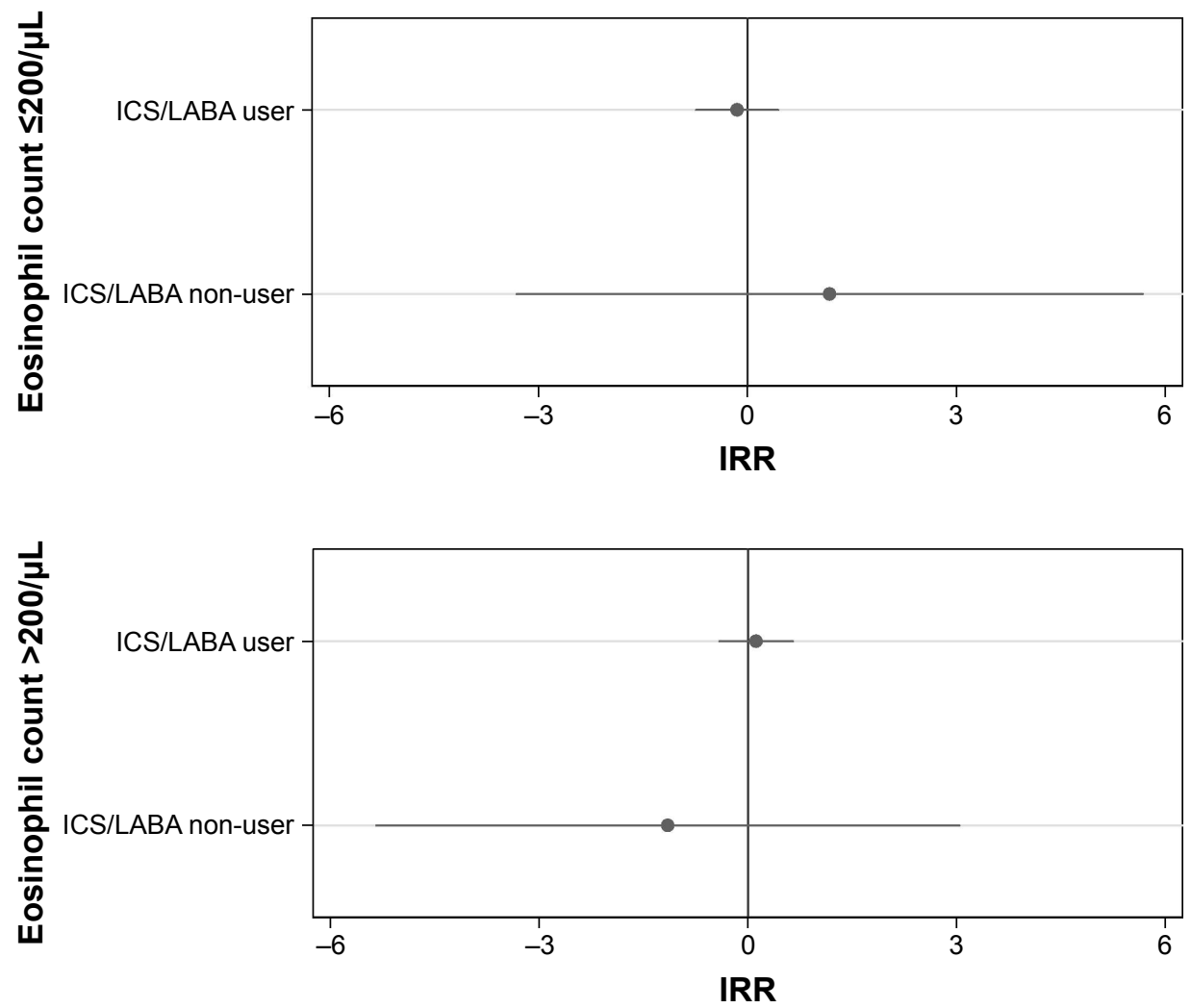

Figure 5 Impact of eosinophil count on moderate-to-severe acute exacerbation rates in COPD patients according to the exposure to ICS/LABA. Abbreviations: ICS, inhaled corticosteroid; LABA, long-acting beta 2 agonist; IRR, incidence rate ratio. 
was diminished by excluding a large proportion of ACOS patients, although the prevalence of ACOS varies based on the qualifying criteria of each region. ${ }^{32}$ Second, this cohort did not have an ICS washout period before enrollment. As a result, approximately half of the patients had been exposed to ICS, which could have decreased the blood eosinophil count at enrollment. ${ }^{27}$ Third, the one-year evaluation period of the FEV 1 changes may have been too short to assess the decline of lung function. Fourth, the analysis did not include adjustment for seasonal variation of eosinophil, which was described in a previous study. ${ }^{33}$

\section{Conclusion}

In patients with non-ACOS COPD, the blood eosinophil count and percent were not associated with $\mathrm{FEV}_{1}$ changes, QoL, frequency of AECOPD, or responsiveness to ICS. Therefore, the clinical implications of the blood eosinophil count should not be overestimated in patients with nonACOS COPD. Further studies are needed to identify the proper phenotypes and relevant biomarkers in this group.

\section{Acknowledgments}

The authors thank the patients who participated in KOCOSS and the centers that provided clinical information on COPD patients.

The list of KOCOSS investigators except authors is as follows: Sun-Young Kyung and Chung Wung Bark of Gachon University Gil Medical Center; Yee Hyung Kim of Kyung Hee University Hospital; Seong Yong Lim of Kangbuk Samsung Hospital, Sungkyunkwan University; Yoonki Hong and Woo Jin Kim of Kangwon National University Hospital; Jaehee Lee of Kyungpook National University Hospital; Yi Yeong Jeong and Ho Choel Kim of Gyeongsang National University Hospital; Kyung Hoon Min and Jae Jung Shim of Korea University Hospital; Hye Sook Choi of Dongguk University Hospital; Soo-Jung Um of Dong-A University Hospital; Jeong Ha Mok and Ki Uk Kim of Pusan National University Hospital; Yong Hyun Kim of Bucheon St Mary's Hospital, The Catholic University of Korea College of Medicine; An-Soo Jang, Sung-Woo Park, and Do-Jin Kim of Soonchunhyang University Bucheon Hospital; Ji-Hyun Lee of Pochon CHA University Hospital; Jae Hyung Lee of Eulji General Hospital; Hye Yun Park of Samsung Medical Center, Sungkyunkwan University Hospital; Sei Won Kim and Yeon-Mok Oh of Ulsan University Asan Hospital; Jick Hwan Hah of Catholic University of Korea St Paul's hospital; Sung Kyoung Kim of St Vincent's Hospital, The Catholic University of Korea College of Medicine; Soo-Taek Uh of Soonchunhyang University Seoul Hospital; Kyeong-Cheol
Shin of Yeungnam University Hospital; Seung Won Ra of Ulsan University Hospital; Sang Ha Kim of Yonsei University Wonju Hospital; Ju Sang Kim of Incheon St Mary's Hospital, The Catholic University of Korea College of Medicine; Jae Hwa Cho of Inha University Hospital; Sung-Soon Lee of Inje University Hospital; Heung Bum Lee and Seoung-Ju Park of Chonbuk National University Hospital; Jaechun Lee of Jeju National University Hospital; Joo Ock Na of Soonchunhyang University Cheonan Hospital; and Tae Rim Shin, Yun Su Sim, So Young Park, Cheol Hong Kim, Myung-Goo Lee, Chang Youl Lee, and Ji Yong Moon of Hallym University Hospital.

\section{Disclosure}

The authors report no conflicts of interest in this work.

\section{References}

1. Guarascio AJ, Ray SM, Finch CK, Self TH. The clinical and economic burden of chronic obstructive pulmonary disease in the USA. Clinicoecon Outcomes Res. 2013;5:235-245.

2. Bourbeau J, Ford G, Zackon H, Pinsky N, Lee J, Ruberto G. Impact on patients' health status following early identification of a COPD exacerbation. Eur Respir J. 2007;30(5):907-913.

3. Donaldson G, Seemungal T, Bhowmik A, Wedzicha J. Relationship between exacerbation frequency and lung function decline in chronic obstructive pulmonary disease. Thorax. 2002;57(10):847-852.

4. Jinjuvadia C, Jinjuvadia R, Mandapakala C, Durairajan N, Liangpunsakul S, Soubani AO. Trends in outcomes, financial burden, and mortality for acute exacerbation of chronic obstructive pulmonary disease (COPD) in the United States from 2002 to 2010. COPD. 2017; 14(1):72-79.

5. Bafadhel M, McKenna S, Terry S, et al. Acute exacerbations of chronic obstructive pulmonary disease: identification of biologic clusters and their biomarkers. Am J Respir Crit Care Med. 2011;184(6):662-671.

6. Thomsen M, Ingebrigtsen TS, Marott JL, et al. Inflammatory biomarkers and exacerbations in chronic obstructive pulmonary disease. JAMA. 2013;309(22):2353-2361.

7. Stolz D, Christ-Crain M, Morgenthaler NG, et al. Copeptin, C-reactive protein, and procalcitonin as prognostic biomarkers in acute exacerbation of COPD. Chest. 2007;131(4):1058-1067.

8. Schleich F, Corhay JL, Louis R. Blood eosinophil count to predict bronchial eosinophilic inflammation in COPD. Eur Respir J. 2016; 45(5):1562-1564.

9. Barnes NC, Sharma R, Lettis S, Calverley PM. Blood eosinophils as a marker of response to inhaled corticosteroids in COPD. Eur Respir J. 2016;37(5):1374-1382.

10. Pascoe S, Locantore N, Dransfield MT, Barnes NC, Pavord ID. Blood eosinophil counts, exacerbations, and response to the addition of inhaled fluticasone furoate to vilanterol in patients with chronic obstructive pulmonary disease: a secondary analysis of data from two parallel randomised controlled trials. Lancet Respir Med. 2015;3(6): 435-442.

11. Bafadhel M, McKenna S, Terry S, et al. Blood eosinophils to direct corticosteroid treatment of exacerbations of chronic obstructive pulmonary disease. Am J Respir Crit Care Med. 2012;186(1):48-55.

12. Vedel-Krogh S, Nielsen SF, Lange P, Vestbo J, Nordestgaard BG. Blood eosinophils and exacerbations in COPD: the Copenhagen General Population Study. Am J Respir Crit Care Med. 2016;193(9):965-974.

13. Pavord ID, Lettis S, Locantore N, et al. Blood eosinophils and inhaled corticosteroid/long-acting beta-2 agonist efficacy in COPD. Thorax. 2016; 71(2):118-125. 
14. Watz H, Tetzlaff K, Wouters EF, et al. Blood eosinophil count and exacerbations in severe chronic obstructive pulmonary disease after withdrawal of inhaled corticosteroids: a post-hoc analysis of the WISDOM trial. Lancet Respir Med. 2016;4(5):390-398.

15. Salturk C, Karakurt Z, Adiguzel N, et al. Does eosinophilic COPD exacerbation have a better patient outcome than non-eosinophilic in the intensive care unit? Int J Chron Obstruct Pulmon Dis. 2015;10: 1837-1846.

16. Soler-Cataluna JJ, Cosio B, Izquierdo JL, et al. Consensus document on the overlap phenotype COPD-asthma in COPD. Arch Bronconeumol. 2012;48(9):331-337.

17. Sin DD, Miravitlles M, Mannino DM, et al. What is asthma-COPD overlap syndrome? Towards a consensus definition from a round-table discussion. Eur Respir J. 2016;48(3):664-673.

18. Golpe R, Sanjuan Lopez P, Cano Jimenez E, Castro Anon O, Perez de Llano LA. Distribution of clinical phenotypes in patients with chronic obstructive pulmonary disease caused by biomass and tobacco smoke. Arch Bronconeumol. 2014;50(8):318-324.

19. Cosio BG, Soriano JB, López-Campos JL, et al; CHAIN Study. Defining the Asthma-COPD Overlap Syndrome in a COPD Cohort. Chest. 2016;149(1):45-52.

20. Marsh SE, Travers J, Weatherall M, et al. Proportional classifications of COPD phenotypes. Thorax. 2008;63(9):761-767.

21. Postma DS, Rabe KF. The Asthma-COPD overlap syndrome. $N$ Engl J Med. 2015;373(13):1241-1249.

22. Bafadhel M, Greening NJ, Harvey-Dunstan TC, et al. Blood eosinophils and outcomes in severe hospitalised exacerbations of COPD. Chest. 2016;150(2):320-328.

23. Lee JY, Chon GR, Rhee CK, et al. Characteristics of patients with chronic obstructive pulmonary disease at the first visit to a pulmonary medical center in Korea: The KOrea COpd Subgroup Study Team Cohort. J Korean Med Sci. 2016;31(4):553-560.

24. From the Global Strategy for the Diagnosis, Management and Prevention of COPD, Global Initiative for Chronic Obstructive Lung Disease (GOLD) [homepage on the Internet]. 2017. Available from: http:// goldcopd.org. Accessed April 5, 2017.
25. Zeiger RS, Schatz M, Li Q, et al. High blood eosinophil count is a risk factor for future asthma exacerbations in adult persistent asthma. J Allergy Clin Immunol Pract. 2014;2(6):741-750.

26. DiSantostefano RL, Hinds D, Van Le H, Barnes NC. Relationship between blood eosinophils and clinical characteristics in a crosssectional study of a US population-based COPD cohort. Respir Med. 2016;112:88-96.

27. George L, Brightling CE. Eosinophilic airway inflammation: role in asthma and chronic obstructive pulmonary disease. Ther Adv Chronic Dis. 2016;7(1):34-51.

28. Miravitlles M, Soler-Cataluna JJ, Calle M, et al. Spanish guideline for COPD (GesEPOC). Update 2014. Arch Bronconeumol. 2014;50(suppl 1): $1-16$.

29. Lavinskiene S, Malakauskas K, Jeroch J, Hoppenot D, Sakalauskas R. Functional activity of peripheral blood eosinophils in allergen-induced late-phase airway inflammation in asthma patients. J Inflamm (Lond). 2015;12:25

30. Pavord ID, Lettis S, Anzueto A, Barnes N. Blood eosinophil count and pneumonia risk in patients with chronic obstructive pulmonary disease: a patient-level meta-analysis. Lancet Respir Med. 2016;4(9):731-741.

31. Nurwidya F, Damayanti T, Yunus F. The role of innate and adaptive immune cells in the immunopathogenesis of chronic obstructive pulmonary disease. Tuberc Respir Dis (Seoul). 2016;79(1):5-13.

32. Wurst KE, Kelly-Reif K, Bushnell GA, Pascoe S, Barnes N. Understanding asthma-chronic obstructive pulmonary disease overlap syndrome. Respir Med. 2016;110:1-11.

33. van der Heide S, de Monchy JGR, de Vries K, Bruggink TM, Kauffman HF. Seasonal variation in airway hyperresponsiveness and natural exposure to house dust mite allergens in patients with asthma. J Allergy ClinImmunol. 1994;93(2):470-475.
International Journal of COPD

\section{Publish your work in this journal}

The International Journal of COPD is an international, peer-reviewed journal of therapeutics and pharmacology focusing on concise rapid reporting of clinical studies and reviews in COPD. Special focus is given to the pathophysiological processes underlying the disease, intervention programs, patient focused education, and self management protocols.

\section{Dovepress}

This journal is indexed on PubMed Central, MedLine and CAS. The manuscript management system is completely online and includes a very quick and fair peer-review system, which is all easy to use. Visit http://www.dovepress.com/testimonials.php to read real quotes from published authors. 